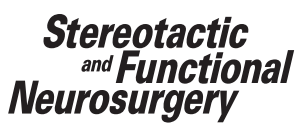

Stereotactic

Neurosurgery
Stereotact Funct Neurosurg 2012;90:347-355

DOI: $\underline{10.1159 / 000341082}$
Received: January 3, 2012

Accepted after revision: June 10, 2012

Published online: August 23, 2012

\title{
A Narrative History of the International Society for Psychiatric Surgery: 1970-1983
}

\author{
Nir Lipsman ${ }^{a}$ Björn A. Meyerson ${ }^{b}$ Andres M. Lozano ${ }^{a}$ \\ a Division of Neurosurgery, Toronto Western Hospital, University of Toronto, Toronto, Ont., Canada; ${ }^{b}$ Department of \\ Clinical Neuroscience, Section CNS Research, Karolinska Institute, Stockholm, Sweden
}

\section{Key Words}

History of neurosurgery · Stereotactic surgery ·

Psychiatric surgery

\begin{abstract}
In order to reconcile the present resurgence of psychiatric neurosurgery with the not-too-distant historic transgressions in the field, one needs to examine the era of transition from crude art to regulated science. In large part, this transition took place in the 1970s with the continued development and widespread acceptance of stereotactic techniques in functional neurosurgery and several hard-fought ideological and academic victories by proponents of the much-maligned field. Established in 1970, the International Society for Psychiatric Surgery (ISPS) sought to gather like-minded surgeons, psychiatrists and other neuroscientists to counter the rising pressure from special interest groups, as well as some in the public and medical realm, who attempted to abolish all forms of surgical management of psychiatric disease. We reviewed the archives of the ISPS, including letters from its founding members and active participants, conference proceedings and minutes from organizational meetings, from throughout its existence from 1970 to 1983 . The archives provide a unique insight into the organization and objectives of the society that kept psychiatric surgery alive in the face of persistent and staunch opposition. We also outline
\end{abstract}

the lessons that current and future functional neurosurgeons can learn from the ISPS, whose key figures, structure and communication, in the non-electronic era, were instrumental for the survival of psychiatric surgery during that critical period.

Copyright $\odot 2012$ S. Karger AG, Basel

\section{Introduction}

Much has been written about the resurgence of surgery for psychiatric disorders in the neurosurgical world. Several reviews have highlighted the promising ongoing trials with application of deep brain stimulation techniques, and there is a cautious yet palpable excitement in the field that surgery for psychiatric indications holds much promise [1-3]. There is also the implicit hope that the advances of today and the future will eclipse, if not overtake, the troubled past of the field.

The 1970s were a turbulent time for psychiatric surgery. Practitioners of the field, both surgeons and psychiatrists, faced no small task to rehabilitate the image of psychiatric surgery from its tarnished reputation at the time. To apply the scientific method and novel stereotactic technology to complex, multifaceted diseases in an era of frequent and strong opposition was the legacy of functional neurosurgeons of that era.

\section{KARGER}

Fax +4161306 1234 E-Mail karger@karger.ch www.karger.com (c) 2012 S. Karger AG, Basel

$1011-6125 / 12 / 0906-0347 \$ 38.00 / 0$

Accessible online at:

www.karger.com/sfn
Dr. Nir Lipsman

Division of Neurosurgery, Toronto Western Hospital, University Health Network

399 Bathurst St., $4 \mathrm{~W}-447$

Toronto, ON M5T 2S8 (Canada)

Tel. +1 647293 0359, E-Mail nir.lipsman@ utoronto.ca 


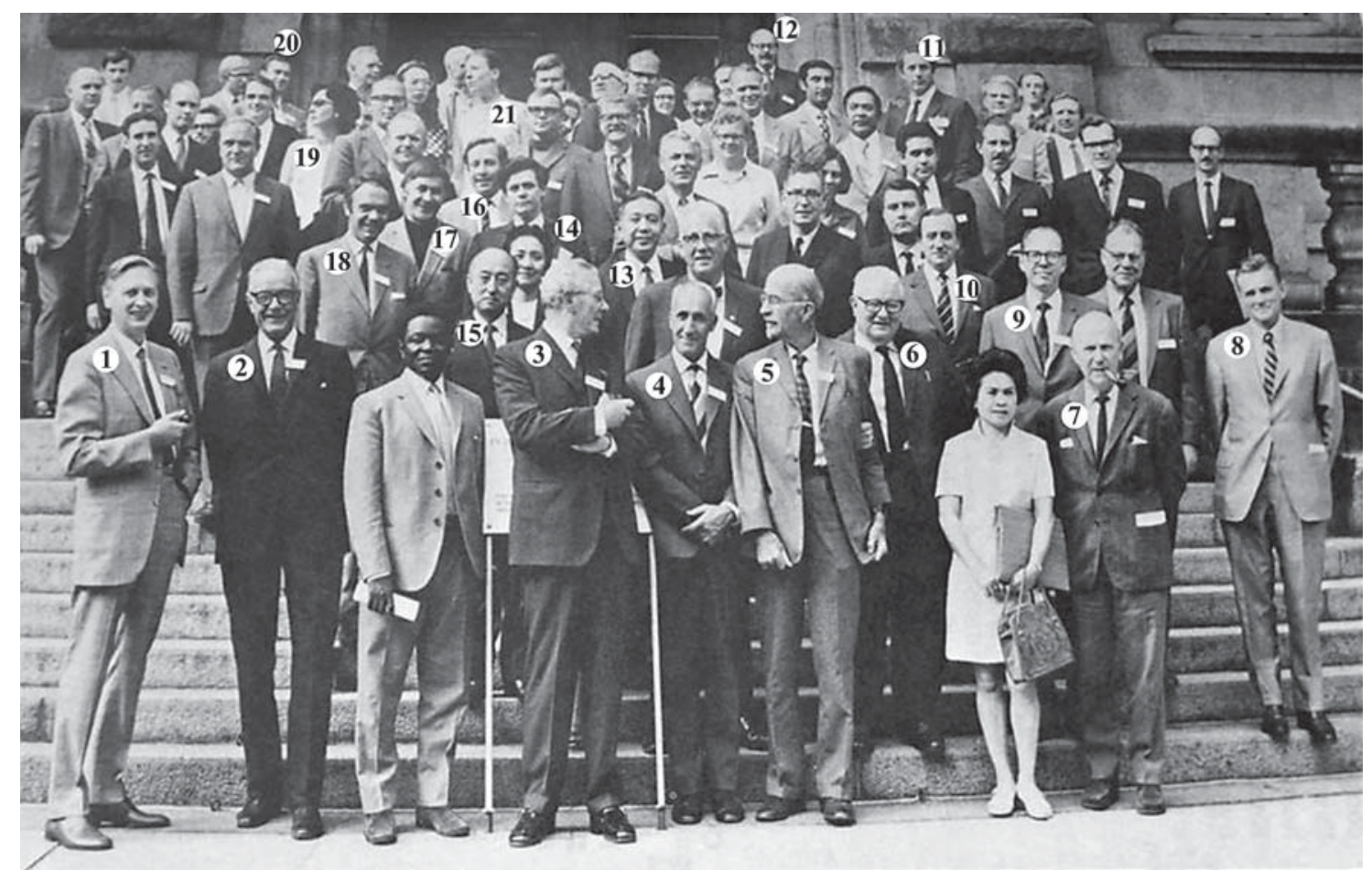

Fig. 1. Photograph of the participants at the 2nd Congress of Psychosurgery in Copenhagen, 1970. (1) Kjeld Vaernet, Denmark; (2) Gosta Rylander, Sweden; (3) Geoffrey Knight, UK; (4) Sixto Obrador, Spain; (5) Walter Freeman, USA; (6) Henry Wycis, USA; (7) Bendt Broager, Denmark; (8) William Scoville, USA; (9) Walpole Lewin, UK; (10) Murray Falconer, UK; (11) Claes Von Essen, Sweden; (12) Blaine Nashold, USA; (13) Keijo Sano, Japan; (14) Edward Hitchcock, UK; (15) Sado Hirose, Japan; (16) Desmond Kelly, UK; (17) Lauri Laitinen, Finland; (18) Jean Siegfried, Switzerland; (19) Maryse Choppy, France; (20) Bjorn Meyerson, Sweden; (21) Gunvor Kullberg, Sweden.

Owing to meticulous record keeping and archiving, we now have access to the minds and practices of the surgeons who kept psychosurgery alive during that fervent period, in Europe, North America and Asia. We recently reviewed the archival material of the Society for Psychosurgery, later renamed the International Society for Psychiatric Surgery (ISPS), from throughout the 1970s and present our findings here.

\section{The Early Days: 1970-1972}

The earliest documents in the archive concern the Second International Conference on Psychosurgery, held in Copenhagen, Denmark, in 1970. Few documents exist that lead up to the event, although it is known from additional sources that initial attempts to label this the First International Conference were met with strong resistance by Walter Freeman, the controversial neuropsychiatrist and proponent of frontal lobotomy [4]. The first international conference, according to Freeman, was held in post-war Lisbon in 1948, and in attendance were both Freeman and Egas Moniz [5]. The correspondence between Freeman and the ISPS executive has now been lost, although we know that the name was indeed changed, and the Second International Conference went ahead as planned, with Freeman himself invited and listed in the conference program as giving a talk titled 'Frontal Lobotomy in Early Schizophrenia: A Long Range Follow-up of 410 Patients'.

By all accounts, including enthusiastic letters to the organizing committee from participants, the Copenhagen Conference was a distinct success (fig. 1). The proceedings from the meeting were subsequently published in 1972, in a collection edited by Hitchcock (UK), Laitinen (Finland) and Vaernet (Denmark) [6]. The ISPS had been founded at the conference with the establishment of a Nominating and Executive Committee as well as a 
draft constitution, although a formal constitution was still 5 years away. By 1970, all conference participants were keenly aware of the controversies surrounding psychiatric surgery, and all had dealt with stark opposition in their native countries. To its participants, the conference represented an oasis of acceptance and allowed a free exchange of surgical experiences. The earliest document in the archive, dated September 1970, is a list of the officers of the ISPS, including Freeman and AlmeidaLima as honorary presidents, William Scoville as President, Vice President Geoffrey Knight and Secretary General Edward Hitchcock. Interestingly, the archives contain a letter from Hitchcock to Almeida-Lima, apologizing for failing to invite him to the event, but nevertheless informing him of his appointment as Honorary President.

Following the success of the Copenhagen conference, word of the Society spread rapidly, leading to a significant increase in membership applications and interest in the field and the group. The officers of the ISPS devoted much of 1970-1971 attempting to capitalize on a clearly interested global academic and public audience and set to work on organizing the Third Conference, tentatively scheduled for 1972. Indeed, in Copenhagen, a running joke amongst participants had been that 'the next conference should be held at a shorter interval than 22 years'. The setting for the third conference, for financial, practical and logistic reasons, was to be Cambridge, with Walpole Lewin as the chief organizer.

All participants in the Copenhagen conference were required to submit formal membership applications to the ISPS, as the budding organization was beginning to take shape. The giants of the field, whose work had fostered psychiatric surgery throughout the 1940s to 1970, were solicited by Hitchcock for their interest in joining, and this correspondence and the applications are windows into the 'who's who' of functional and psychiatric surgery of the time. These include applications from such surgical luminaries as Manuel Velasco-Suarez, as well as Lars Leksell and Sixto Obrador. The latter, for example, lists the following under 'Special Interests': 'Neurophysiological studies with deep recording and stimulation using the techniques of J.M.R. Delgado in the human brain'. Delgado, who the archives tell us declined to join the ISPS, had by then just moved to Madrid from Yale. Hitchcock's letter took an entire month to reach Delgado, who then insisted that he may be interested in attending and possibly presenting at future meetings but that he was uninterested in full membership. Obrador's inclusion of Delgado's techniques as his sole 'Special Interest' in his membership application highlights the reason behind Delgado's recruitment to Madrid and is prescient, as it foreshadows the close relationship between a neurosurgeon and a neurophysiologist.

The period between Copenhagen and Cambridge was a fruitful and productive one for the organizing and program committee, as they sifted through numerous applications and determined the theme for the coming conference. It is from this period that the archives contain applications from the likes of John Bartlett, Claude Bertrand, Paul Bridges, Jan Gybels and Paul Cosyns, individuals who were firmly and actively involved in psychiatric surgery and whose inclusion in the ISPS illustrated two essential points. The first is that reaching out to psychiatrists was found to be a critical component in the survival of the organization and the field (discussed below). The second is the global reach of the organization, which attempted to secure memberships from individuals around the world. Indeed, applications for membership arrived from Japan, India, Sweden, Finland, the UK, Italy, Czechoslovakia, USSR, Brazil, Mexico and others.

It is also clear from the archives that a small number of people were responsible for maintaining the ISPS and keeping it running smoothly. Recurring names occur throughout the documents and include the pioneers of the field, whose affection and respect for each other was evident with every correspondence. Figures such as Ken Livingstone, Thomas Ballantine, William Scoville, William Sweet, Björn Meyerson, Lauri Laitinen, Kjeld Vaernet and Sixto Obrador spent much of their time and energy to ensure frequent and productive meetings and continued progress in the field. The Cambridge conference, scheduled for 1972, was seen as a vital meeting at which the momentum gained in Copenhagen could be harnessed. Freeman, who was present in 1970, passed away in May of 1972, just as preparations for Cambridge were being made. As testimony to his interest and passion for psychiatric surgery, he remained active in the field even in the months and weeks leading up to his death. The archives contain several letters from Freeman to Hitchcock, who was helping to organize the Cambridge meeting, expressing his desire to attend and present his latest work. In his final letter to Hitchcock just 2 months before his death, Freeman laments his inability to attend the Cambridge Congress due to failing health, although he assures Hitchcock that he will nevertheless submit an abstract.

The vast majority of the archived documents are letters and memos among the executive committee. Some letters are dated mere days apart and indicated a commit- 
ment on the part of members to sustain the ISPS. No detail was beyond discussion, as ISPS officers debated details such as the ISPS logo, the colour of the seasonal Bulletin which contained Society announcements, as well as the name of the organization, potential members and the make-up of the conference program. As ISPS President during the 1970-1972 period, Scoville frequently remarked how necessary these details were to the integrity of the ISPS and thanked Hitchcock and Livingstone profusely for shouldering the burden of maintaining and organizing the developing Society.

\section{Gaining Momentum: 1972-1975}

The archives inform a time period during which the entire practice of psychiatric neurosurgery was in doubt. The 1960s had ushered in an era of counter-culture and political and cultural change that, in many respects, targeted a perceived authoritarian and paternalistic medical model. Surgery on psychiatric patients was viewed as the ultimate expression of this paternalism, and to many in the public and academic medical realm, this represented a gross abuse of power in its most extreme form. Concerns arose that government bodies would turn to neurosurgeons and psychiatrists to use 'mind-altering' surgery for political gain or that prisoners and the involuntarily institutionalized would be fodder for experimental surgery. The earlier work of Freeman and Watts and the thousands of patients who had undergone lobotomy added fuel to the fire, with many in the USA and several other countries calling for a complete ban on psychiatric surgery. The archives provide a unique perspective on these events, as the ISPS was formed as a direct response to these developments in an effort to quell academic nerves and prove the efficacy and safety of psychiatric surgery.

The ISPS executive was keenly aware of the burden it now carried. Not only was it the public face of psychiatric surgery, but its every meeting and publication would now be scrutinized by opponents of the field. As such, no detail was deemed too small for debate, as it could represent a potential weakness in the Society's armour. Several letters from Scoville, for example, focused on whether the ISPS should name the Cambridge meeting a 'Conference' or a 'Congress'. Perhaps the most vigorous debate in the archives surrounded the term 'psychosurgery' and, related to this, whether the Society should be renamed from the original 'International Society for Psychosurgery'. The officers of the Society fell into two camps. Some felt that the term 'psychosurgery' was too politically and emotionally loaded and that an effort should be made to distance the group from the term if the image of psychiatric surgery was to be rehabilitated in the public eye. One member wrote to Scoville, 'Do you, Dr. Scoville, cut into your patients psyche? Into their soul?'. Other members were staunchly opposed to changing the name, insisting that to change it equated to admitting that such procedures were in some way inherently wrong. 'Rehabilitation is better than rejection', wrote Dr. J.R. Bartlett of the UK. One can further see from the cover images of Bulletin that the name of the Society underwent several incarnations before the name International Society for Psychiatric Surgery was settled on, at the Cambridge meeting, in 1972 (fig. 2). It was seen by most to be a compromise that the majority of members eventually accepted, albeit some begrudgingly.

In 1972 there were 154 members of the ISPS, and with 101 officially registered participants, the Cambridge meeting was significantly better attended than Copenhagen (fig. 3) and was a tribute to the growing reach of the ISPS as well as the increasing safety and efficacy of psychiatric surgery. Stereotactic methods had by that point supplanted open approaches, and an increasing number of talks in Cambridge focused on new surgical techniques [7]. Still lacking, however, was a distinct and universal psychiatric classification system, which would come in the form of the third version of the Diagnostic and Statistical Manual in 1980, and the inclusion in the program of several prominent psychiatrists addressed this issue. By all accounts, Cambridge had achieved its aims of solidifying the ISPS and establishing it as a society distinct from the World Society for Stereotactic and Functional Neurosurgery. Although some sought to amalgamate the two, the officers of the ISPS stood firm in preventing the ISPS from being 'swallowed', in the words of Scoville, by a larger society. If the ISPS was to achieve its objectives, it was to remain autonomous and separate from the other neurosurgical organizations.

The next meeting, scheduled for Madrid in 1975 and to be hosted by Obrador, was to tackle new surgical approaches and new challenges for the psychiatric surgeon [8]. It was to be a seminal meeting for the ISPS for several reasons. Having been born in Copenhagen in 1970 as a Society 'to examine the scientific basis of psychosurgery', the ISPS had existed since then without a constitution. Earlier meetings had established the organization and structure of the Society, including a successful meeting in Cambridge, but no formal charter existed that outlined membership and society rules and regulations. The officers of the ISPS spent much of their time 

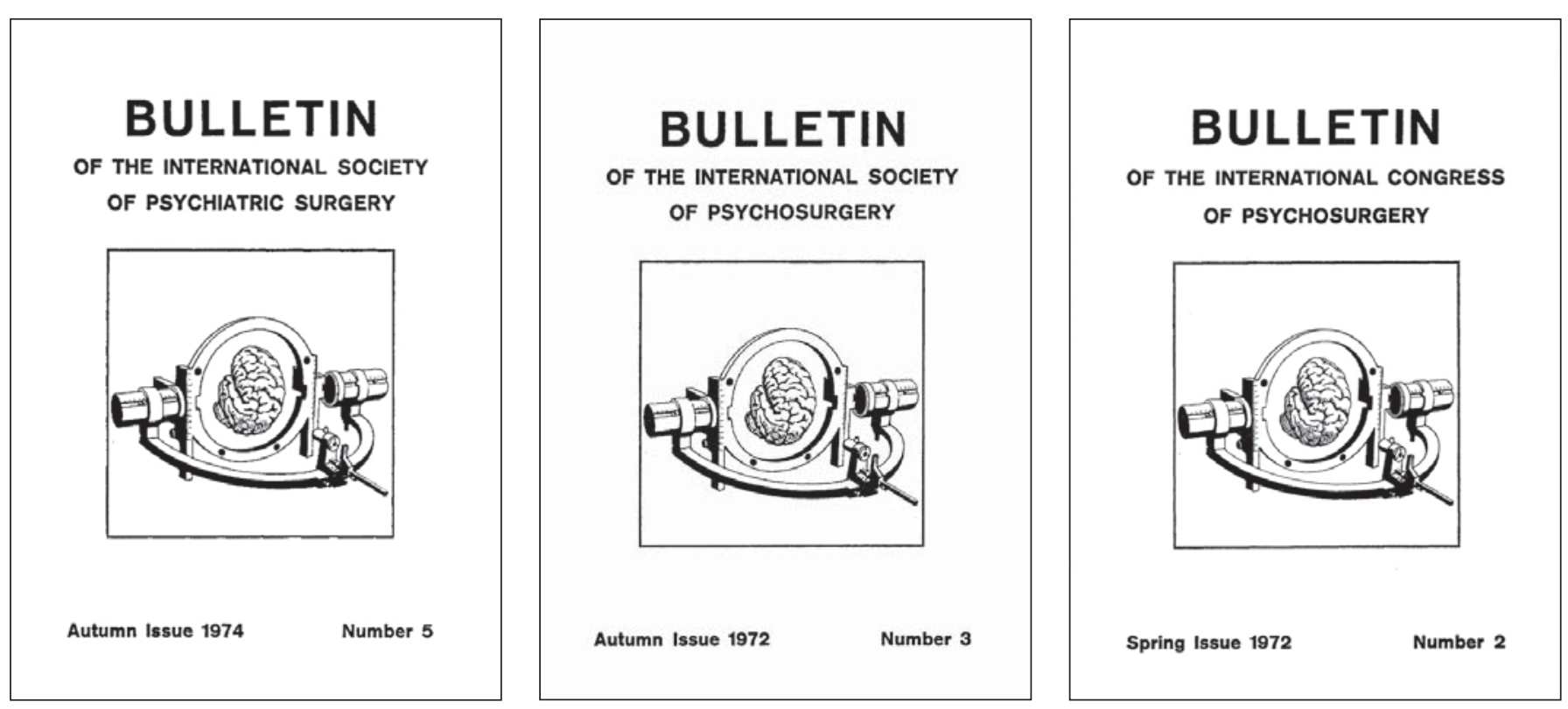

Fig. 2. Bulletin was the seasonal forum for announcements of the Society, and the various incarnations of the Society's name can be seen on the cover. The name of the Society underwent many changes, with much attention paid to the perceived and actual meanings of 'congress' and 'psychosurgery'. There were three changes over a period of 2 years.

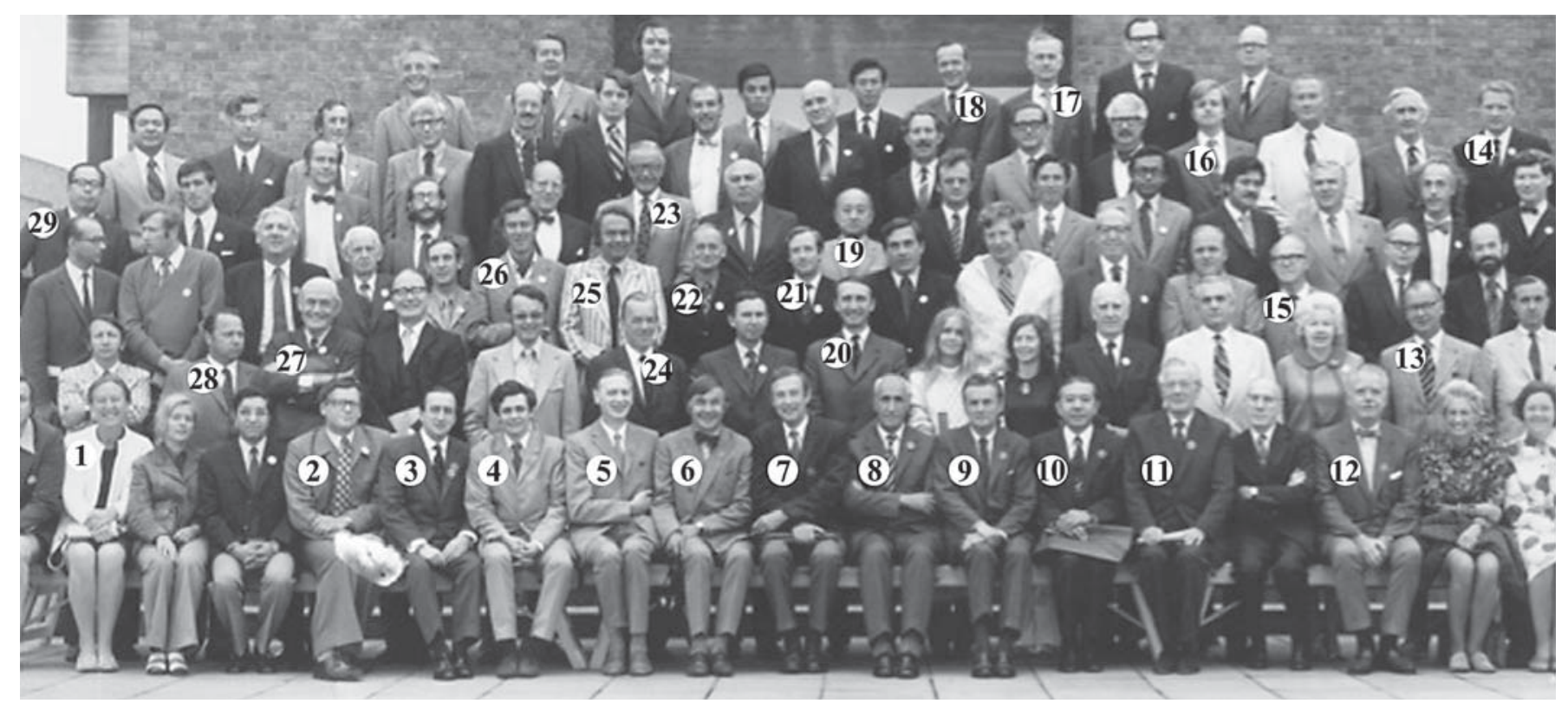

Fig. 3. Photograph of the participants at the 3rd Congress of Psychosurgery in Cambridge, 1972. (1) Gunvor Kullberg, Sweden; (2) Paul Cosyns, Belgium; (3) Murray Falconer, UK; (4) Eduard Hitchcock, UK; (5) Kjeld Vaernet, Denmark; (6) Lauri Laitinen, Finland; (7) Ken Livingstone, Canada; (8) Sixto Obrador, Spain; (9) William Scoville, USA; (10) Keijo Sano, Japan; (11) Geoffrey Knight, UK; (12) Tom Ballantine, USA; (13) Walpole Lewin, UK; (14) Gerd Dieckmann, Germany; (15) Bendt Broager, Denmark;
(16) Richard Perrin, Canada; (17) William Sweet, USA; (18) Kurt West, Sweden; (19) Sado Hirose, Japan; (20) Paul Bridges, UK; (21) Desmond Kelly, UK; (22) Jan Gybels, Belgium; (23) Gosta Rylander, Sweden; (24) Jan Van Manen, The Netherlands; (25) Jean Siegfried, Switzerland; (26) Bjorn Meyerson, Sweden; (27) William Sargent, UK; (28) Rolf Hassler, Germany; (29) Hirotaro Narabayashi, Japan. 
after Cambridge and prior to Madrid, with Scoville continuing on as President, drafting a constitution that was ultimately unanimously ratified in Madrid in 1975. Few documents in the ISPS archives contain as many edits, scratches, debates and addendums as the drafts of the constitution. With the confirmation of the constitution, the ISPS was officially founded, and a notice of the 'new' organization was sent out to numerous neurosurgical and psychiatric journals. Obrador, now ISPS President at the Fourth Congress, also oversaw the confirmation of reports from the Ethics Committee and the Committee on Terminology and Assessment. The latter especially grew out of increasing criticism that neurosurgeons participating in psychiatric surgery failed to appropriately document their pre- and post-operative patient assessments. Efforts to formalize these assessments, informed by psychiatric consultation, established a precedent still in place today, without which the ethical conduct of psychiatric surgery could not take place [9]. Madrid also saw the largest participation at any psychiatric surgery conference that preceded or followed it. There were 209 people registered for the Madrid conference, with the largest proportion coming from Spain itself. Indeed, in a membership census completed in 1977, the largest proportion of ISPS members, $41 / 165$ (25\%), originated from Spain.

The archives do not contain the program from the Madrid conference, although it is clear from subsequent correspondence that the focus remained on proving the efficacy and safety of psychiatric surgical procedures. Furthermore, the great majority of the presentations were subsequently published in the proceedings from the meeting [8]. Although the officers of the ISPS had attempted to be egalitarian in their nomination and selection of the new Board of Directors, there was some dissent, with prominent figures such as J. Le Beau from the Sorbonne University of Paris arguing that France, for example, remained under-represented, despite her contributions to psychiatric neurosurgery.

\section{Taking Stock: 1975-1978}

Between 1975 and 1978, the ISPS flourished, for several reasons. The Madrid conference had been a clear success, from both organizational and scientific perspectives. Never before had so many neurosurgeons, psychiatrists, neurophysiologists, anatomists and neuroscientists gathered to discuss the role of surgery in mental illness. Individuals who had previously been unable to attend, such as Delgado, had participated, lending credibility and prestige to the already high-profile event. The inclusion and explicit recruitment of non-neurosurgeons to the ISPS was a calculated move by the officers of the ISPS. Myriad letters exchanged between them highlight the importance of a multidisciplinary presence in Madrid, as nearly every executive member recognized the importance of reaching out to the wider neuroscience community if the science behind psychiatric surgery should be taken seriously.

In 1977, there was also evidence that the tide against psychiatric surgery was beginning to turn, both in the USA and abroad. The National Commission for the Protection of Human Subjects of Biomedical and Behavioral Research had been established to study the question of psychiatric surgery and to determine whether there is just cause to prohibit these procedures. The commission outlined the arguments of prominent opponents of psychiatric surgery, including Peter Breggin, and reviewed the findings of individual states, such as Oregon and California, who had placed significant restrictions on surgical procedures for psychiatric indications in the early 1970s. Despite these criticisms and regulations, the Commission 'determined unanimously that there are circumstances under which psychosurgical procedures may be appropriately performed' [10]. The finding that 'psychosurgery should not be prohibited categorically' was a boost for the ISPS and for many of its officers, and it was seen as evidence that the objectives of the Society were being met.

The ISPS Board of Directors met in Sao Paulo during the Congress of Neurological Surgeons in 1977 to determine the next steps. Madrid had been successful, and the ISPS now had 169 members. The Fifth Congress was scheduled for Boston, under the supervision of Tom Ballantine, and would represent the first meeting on North American soil. The theme proposed by Ballantine, 'Alterations in Brain Function: Neurochemical Aspects of Stimulation and Ablation', was approved without debate, and arguably could be the theme of a Functional Neurosurgery conference 35 years from then. At the time, Ballantine had solicited pharmaceutical companies to sponsor the conference and had predicted that 500 neuroscientists would attend. Although a special meeting dealing with surgery for mental illness in Sao Paulo had been well attended [11], it appears from letters leading up to 1978 that registration for the Boston meeting had been slow. Indeed, in an undated letter following the 1978 Boston meeting, Björn Meyerson commented whether the relatively 'small number of neurosurgeons involved in psy- 
chosurgery' could justify additional meetings. Such comments foreshadow the discussions to take place just a few years later. The Boston meeting did proceed, however, but not without controversy. Students protesting against psychiatric surgery circled the conference building on the Harvard campus, with conference attendees advised not to leave the building unescorted by security personnel. The proceedings from the Boston meeting were subsequently published in 1979, edited by Hitchcock, Ballantine and Meyerson [12].

It appears, on close examination of the archives, that 1978 was a turning point for the ISPS. Obrador's death from liver cancer in April of that year, as well as the sudden and unexplained resignation of Lauri Laitinen, the President elect of the ISPS, 2 months prior to the Boston meeting, resulted in a leadership void that left the Board of Directors scrambling for a replacement. Debates ensued about who should assume the role, with Hitchcock throwing his vote behind Ballantine, and others including Scoville, much to Hitchcock's disagreement, nominating Walpole Lewin, the President of the Cambridge Congress of 1972. Ballantine would eventually win the vote and proceed to oversee a relatively successful Boston conference, although it appeared to many that the days of the ISPS were indeed numbered. Despite this, several officers, including the eventual President of the World Society for Stereotactic and Functional Neurosurgery Jean Siegfried and stalwart member Edward Hitchcock, saw the value of an 'all psychiatric surgery' organization, where valid research would not be lost among other advances in functional neurosurgery. Further, although some progress had been made on the political front for psychiatric surgery, William Scoville was at the time reporting 'tough sledding' and being the 'sole survivor in Connecticut' to perform psychiatric surgery, as late as 1980. In response, ISPS President Tom Ballantine provided a different perspective, citing he was 'busier than I have ever been in that particular field!' and noted a 'noticeable warmer' attitude in the USA towards psychiatric surgery. Clearly, for the ISPS Executive, additional meetings were required and planned, including a fateful one for the ISPS in Zurich in 1981, to discuss matters further and to determine the location and date of the Sixth Congress, tentatively scheduled for Stockholm in 1982.

Among the most valuable documents in the archives are the results of a survey, carried out in 1981 and commissioned by Meyerson, that examined the practice of functional neurosurgeons interested in psychiatric disease. In addition to providing a snapshot of contempo- rary surgical practices, the results shed light on the kinds of questions that neurosurgeons were asking and what they deemed to be important avenues of further research. Of 180 surveys distributed, Meyerson received 40 responses, a not-too impressive response rate, but one that is nevertheless informative. The main indications for psychiatric surgery were obsessive-compulsive disorder, followed by 'behavioural problems', such as aggression, and then depression. Only 3 of the 40 reported performing 'intracerebral stimulation' for psychiatric indications. When asked if over the next few years, they foresaw changes in the number of patients admitted for psychosurgical treatment, 1 of 3 predicted an increase, 1 of 3 a decrease and another 1 of 3 no change. Most informative for Meyerson, who was preparing for a meeting in Stockholm, 28 of the 40 responders indicated a continued need for an ISPS congress, with the majority indicating participation. When asked for suggestions for topics at future congresses, comments included 'ethical problems in psychosurgery', 'stimulation therapy', 'animal models' and 'indications for surgery', all of which remain relevant today.

\section{Winding Down: 1978-1983}

The earliest formal mention in the archives of the future of the ISPS is from the minutes of a meeting of the Board of Directors in Zurich in 1981, held to coincide with the World Society for Stereotactic and Functional Neurosurgery that year. William Sweet comments that the future of the society beyond 1983, the sixth congress, needs to be discussed and thought about early. Even prior to this, officers, including Meyerson, suggested that a paucity of research and warming public attitudes towards psychosurgery hinted at a redundancy of the ISPS; perhaps it was simply no longer needed. In Zurich, the minutes reported that 'Meyerson had doubts about the need of the Stockholm meeting' and that 'Sweet proposed to organize [the IVth ISPS Congress] in connection with one International Neurosurgery Meeting for example the European Congress of Neurosurgery'.

Such comments from William Sweet are particularly telling given the tone of his earlier correspondence leading up to the Madrid congress in 1975. Those earlier letters possessed a sense of immediacy and urgency; they implored fellow ISPS members to submit abstracts and participate in Madrid and insisted that only papers that are 'unusually critically documented' should be included in the conference program. He further reported at the 
time incidents of 'harassment of senior neurosurgeons' who were engaged in psychiatric surgery and alluded to 'political developments in the States and elsewhere' that threatened the field in the 1970s. Therefore, Sweet's comments in 1981 are a sharp contrast and represent either a declining momentum for the ISPS or the belief that the objectives of the organization had been achieved. Given the support of Meyerson, Siegfried and eventually Ballantine, most likely the latter is the best explanation. It was Ballantine who suggested that the next congress, which was to be the sixth ISPS meeting, should be held in conjunction with the World Congress of Psychiatry, in Vienna in 1983. Although still 2 years away, the suggestion was prescient and ultimately came to pass. That meeting, attended by a mere 20 members, and organized by Meyerson and Ballantine, would be the last official meeting of the ISPS.

Negotiations with the World Congress of Psychiatry began in earnest, with Desmond Kelly acting as the liaison between the ISPS and Prof. Pichot of Barcelona, the President of the World Congress of Psychiatry. In the end, the 1983 conference saw two back-to-back symposia focused on psychiatric surgery, where the stars of the field stated their case in front of the world's psychiatrists. Ballantine presented 'Twenty years of stereotactic cingulotomy', and John Bartlett presented 'Indications for psychiatric surgery', among other presentations. The officers of the ISPS made it clear that they agreed to participate because inclusion in a psychiatric conference allowed them to present their research to the physicians responsible for referring patients. They needed to be convinced. Lauri Laitinen wrote: 'Most readers of the psychosurgical papers are psychiatrists ... many of them even doubt whether surgery has any place in the psychiatric therapy. It is important to state clearly the diagnosis, the grade of severity, and the duration of illness, as well as all previous treatments.' What was needed, in other words, was data and properly designed trials, with proper psychiatric assessments both pre- and post-operatively. The ISPS had spent over a decade trying to ensure that the psychiatric, medical, political and public communities would take their treatments seriously. In many ways, by holding court at a global psychiatric congress, those goals had been achieved.

The archives contain no evidence of any further plans to organize a meeting after that in Vienna in 1982. Mention of the ISPS can be seen in letters from the mid-1980s, in which Ballantine and Siegfried comment on the continued necessity of the Society and the dissemination of scientific results. Although there are discussions of changing the name again, and hence continuing to evolve, no firm decision was made, and in the end, the archives conclude with a nod to history. American psychiatrist and author Eliot Valenstein wrote to the ISPS officers searching for Freeman's original letter requesting that the first congress be renamed the second congress in light of his attendance at the original psychiatric surgery conference in Lisbon in 1948. He was told, by both Siegfried and Hitchcock, with the honesty and candor that is so common in their frequent correspondence, that no such letter exists in the archives and that perhaps he should continue searching.

\section{Lessons Learned}

In one of his many letters from the archives, William Scoville writes, '[Cambridge Program President] Livingstone has sought basic scientists rather than surgeons for our guest speakers in order to convince the world and ourselves that we indeed are a Society of dedicated scientists rather than trigger happy barber surgeons'. It can be argued that the backlash against psychiatric surgery was due not only to the haphazard use and abuse of novel surgical techniques but also to the lack of organization in the field, leading to poor methodology and a failure to adequately report results. Although surgeons and psychiatrists had forged alliances previously, Freeman and Watts, and Moniz and De Almeida being but two examples, the ISPS sought to bring the relationship closer, formalize it and make it inextricable. 'A restrictive approach to membership', wrote Bartlett, 'will inevitably be regarded with suspicion by general psychiatrists who must, of course, feel confidence before referring patients for treatment'.

The archives reveal the inner workings of a Society whose existence helped make contemporary psychiatric surgery practice possible. Several lessons can be derived, and these apply not only to establishing a successful organization but also to ensuring the establishment of a subspecialty and field. These lessons include the importance of organization and communication, anticipating challenges, forging relationships with multiple disciplines, setting goals and establishing a legacy.

What began as a meeting of like-minded surgeons in Copenhagen in 1970 grew into several global congresses with hundreds of members and interest globally. Today, over 40 years since Copenhagen, clinical trials of psychiatric surgery for several different indications are being conducted around the world. Surely, as more sophisticat- 
ed measures of brain function and physiology are developed, and as technology becomes smaller, more efficient and safer, the ability of surgeons to modify behavioural and mood disorders will only improve. The original founders of the ISPS, which at its peak extended its reach and interests to nearly every country engaged in functional neurosurgery, would surely be proud that the principles they so humbly formulated in their earliest letters have now been taken up by a new generation of neurosurgeons.

\section{References}

1 Goodman WK, Alterman RL: Deep brain stimulation for intractable psychiatric disorders. Annu Rev Med 2012;63:511-524.

-2 Howland RH, Shutt LS, Berman SR, Spotts CR, Denko T: The emerging use of technology for the treatment of depression and other neuropsychiatric disorders. Ann Clin Psychiatry 2011;23:48-62.

$\checkmark 3$ Ward HE, Hwynn N, Okun MS: Update on deep brain stimulation for neuropsychiatric disorders. Neurobiol Dis 2010;38:346-353.

4 El-Hai J: The Lobotomist: A Maverick Medical Genius and His Tragic Quest to Rid the World of Mental Illness. New York, Wiley \& Sons, 2005.

5 Psychosurgery. 1st International Conference (August 4th-7th, 1948). Lisbon, Livraria Luso-Espanhola, 1949.
6 Hitchcock E, Laitinen L, Vaernet K (eds): Psychosurgery. Proceedings of the 2nd International Conference on Psychosurgery, Copenhagen 1970. Springfield, Thomas, 1972.

7 Laitinen L, Livingston K (eds): Surgical Approaches in Psychiatry. Proceedings of the 3rd International Congress of Psychosurgery, Cambridge 1972. Lancaster, Medical and Technical Publishing, 1973.

8 Sweet W, Obrador S, Martin-Rodriguez JP (eds): Neurosurgical Treatment in Psychiatry, Pain and Epilepsy. Proceedings of the 4 th Congress of Psychiatric Surgery, Madrid 1975. Baltimore, University Park Press, 1977.

9 Nuttin B, Gybels J, Cosyns P, Gabriels L, Meyerson B, Andreewitch S, Rasmussen SA, Greenberg B, Friehs G, Rezai AR, Montgomery E, Malone D, Fins JJ: Deep brain stimulation for psychiatric disorders. Neurosurg Clin N Am 2003;14:xv-xvi.
10 National Commission for the Protection of Human Subjects of Biomedical and Behavioral Research: Psychosurgery. Washington, Federal Register, 1977.

11 Carrea R (ed): Proceedings of the Sixth International Congress of Neurological Surgery, São Paulo 1977. International Congress Series No. 433. Amsterdam, Excerpta Medica, 1978 .

12 Hitchcock ER, Ballantine HT, Meyerson BA (eds): Modern Concepts in Psychiatric Surgery. Proceedings of the 5th World Congress of Psychiatric Surgery, Boston 1978. New York, Elsevier/North-Holland Biomedical Press, 1979. 